\title{
In vitro evaluation of marginal and internal adaptation of class II CAD/CAM ceramic restorations with different resinous bases and interface treatments
}

\author{
María José Sandoval ${ }^{1}$ - Giovanni Tommaso Rocca ${ }^{1}$ • Ivo Krejci $^{1}$ • Michael Mandikos ${ }^{2}$. \\ Didier Dietschi ${ }^{1,3}$
}

Received: 28 October 2013 / Accepted: 11 March 2015 /Published online: 16 April 2015

(C) Springer-Verlag Berlin Heidelberg 2015

\begin{abstract}
Objectives This in vitro study evaluated the influence of different composite bases and surface treatments on marginal and internal adaptation of class II CEREC CAD/CAM ceramic inlays, before and after simulated occlusal loading. Methods Thirty-two IPS Empress CAD class II inlays (MO or OD) ( $n=8$ /group) were placed on third molars, with margins $1 \mathrm{~mm}$ below the cementum-enamel junction (CEJ), following different cavity treatments. These treatments were non-liner (control group), a flowable composite liner (Premise flow) sandblasted or treated with soft air abrasion and a restorative composite liner (Premise) sandblasted. The restorations were then luted with Premise. All specimens were submitted to 1, 000,000 cycles with a $100-\mathrm{N}$ eccentric load. The tooth restoration margins were analysed semi-quantitatively by SEM pre- and post-loading. The internal adaptation was also evaluated after test completion.

Results The percentage of satisfactory marginal adaptation varied from 75 to $87 \%$ pre-loading and 62 to $72 \%$ postloading in occlusal enamel, from 71 to $83 \%$ pre-loading and 52 to $63 \%$ post-loading in proximal enamel, and from 68 to $88 \%$ pre-loading and 43 to $66 \%$ post-loading in cervical
\end{abstract}

Didier Dietschi

didier.dietschi@unige.ch

1 Division of Cariology and Endodontology, Dental School, University of Geneva, 19 Rue Barthélémy Menn, 1205 Geneva, Switzerland

2 Brisbane Prosthodontics, Graceville, Queensland 4075, Australia

3 Department for the Practice of the General Dentistry, Case Western University, Cleveland, OH, USA dentin. There were no significant differences among groups. The percentages of satisfactory tooth-composite internal adaptation varied from 81 to $98 \%$ in occlusal dentin, from 63 to $90 \%$ in axial dentin, and from 71 to $84 \%$ in cervical dentin without any statistical difference.

Conclusions The results of the present study support the use of flowable or restorative composites as a liner underneath ceramic $\mathrm{CAD} / \mathrm{CAM}$ inlays, producing marginal and internal adaptation which is not different from restorations placed directly on dentin. Soft air abrasion proved not to be different from sandblasting for treating cavities before cementation. Clinical relevance The results of this in vitro test validate the increasing use of a flowable base/liner underneath $\mathrm{CAD} / \mathrm{CAM}$ ceramic inlays to optimise tissue conservation and clinical procedures; in this case, soft air abrasion is recommended as a pre-cementation step.

Keywords Ceramic inlays $\cdot$ Class II $\cdot \mathrm{CAD} / \mathrm{CAM}$. CEREC $\cdot$ Base $\cdot$ Liner $\cdot$ Interface treatment $\cdot$ Marginal adaptation $\cdot$ Fatigue

\section{Introduction}

The success of tooth-coloured restorations, whether direct or indirect, using composites and ceramics, greatly depends on the quality and stability of their marginal adaptation $[1,2]$. With direct adhesive restorations, resin composite polymerisation [3-6] can induce immediate adhesive or cohesive failures when shrinkage stress exceeds the bond strength of the adhesive interface or the tooth's cohesive strength. This results in a lower restoration quality or the need to replace the restoration. Such initial failures are also likely to subsequently worsen and expand due to functional stresses [7]. The 
potential occurrence of such defects is directly related to increasing cavity size and depth [8-13]. Apart from various protocols aimed to limit the risk of defective restoration adaptation with a direct approach [14-17], the use of indirect porcelain or resin composite restorations is still the most common approach for reducing the adverse effects of bulk polymerisation contraction in large cavities as the volume of composite resin is strictly limited to the cementing gap [8, 18-20].

In large and deep cavities (close to or below the cementoenamel junction), the application of an adhesive resin liner underneath the indirect restoration to relocate deep cervical margins represents an interesting non-invasive alternative to traditional surgical crown lengthening [21] and facilitates impression technique and cementation procedures. The base also fulfils additional requirements such as reinforcing undermined cusps, filling undercuts, providing the necessary geometry for an inlay/onlay restoration and maintaining dentin seal during the temporary phase in true indirect restorations [22]. Poor cavity sealing may result in mechanical, thermal and bacterial irritation, possibly leading to pulpal pathology [23, 24]. Moreover, without the presence of a liner or base, the removal of the temporary restoration, re-exposure and cleaning of the prepared dentin surfaces, as well the positive pressure induced during inlay/onlay insertion, will frequently induce discomfort in patients and thus demands anaesthesia, which is generally not needed with lined cavities. Therefore, the application of a base underneath indirect or chair-side inlays and onlays has clear technical, biological and clinical advantages over the classical protocol, which leaves dentin unsealed until the restoration cementation $[23,24]$.

The elastic modulus $(E)$ of restorative materials, among other physical properties, is of great importance to evaluate their potential stress absorbing and tooth reinforcement effects $[12,13,25-27]$. The role of the base/liner is of paramount importance as depending on its material stiffness and deformation capability, stresses within the adhesive interface are supposedly lowered (when elastic modulus is lower than or matching the one of the surrounding structures) or are just passed onto the next interface without absorption (high elastic modulus) [27]. It was actually suggested that an intermediate elastic modulus (7-8 GPa, which is about half of the elastic modulus of dentin) has the best potential for a liner to improve restoration adaptation of indirect composite restorations [12, $13,22]$. In regard to the restoration itself, the stiffness also has an impact on residual tooth structure deformation, depending on the cavity dimensions and tooth configuration [9-11,28]. However, the optimal liner characteristics for use underneath ceramic $\mathrm{CAD} / \mathrm{CAM}$ restorations (higher or lower elastic modulus) remain to be established.

The interface quality between the resinous base and luting composite or between the luting composite and inlay resulting from micro-mechanical retention or copolymerisation was also found to be critical for restoration quality and success [29,
30]. A pre-treatment of the cavity and base/liner has to be performed following removal of temporisation and before cementation. This can be achieved using pumice or more often nowadays, soft air abrasion and sandblasting (airborne-particle abrasion). These procedures aim to clean and chemomechanically activate the composite liner/base to improve micro-mechanical retention or adhesion of the restoration $[28,31]$. Although used daily by a large number of practitioners, the respective influence of soft air abrasion and sandblasting on restoration interface quality is not well known and only limited evidence is available [32].

The performance of indirect composite and ceramic restorations generated either chair-side (i.e. $\mathrm{CAD} / \mathrm{CAM}$ ) or in a laboratory, is well documented [2, 33, 34]. Collectively, performance can be considered satisfactory with median annual failure rates ranging from $1.1 \%$ (CAD/CAM option) to $2.0 \%$ (composite option). CAD/CAM techniques have also seen remarkable developments in terms of precision and clinical application. There have been significant improvements in software management of function and anatomy, and this explains their increasing current usage [34-39].

The aim of this in vitro study was to evaluate the influence of different composite bases and surface treatments on the marginal and internal adaptation of class II CEREC CAD/ CAM ceramic inlays, before and after occlusal loading. The null hypothesis was that there is no difference in the marginal and internal adaptation of class II ceramic inlays with or without composite bases of various elastic moduli and following two different interface treatments.

\section{Materials and methods}

Figure 1 summarises the experimental and restorative procedure flow.

\section{Tooth preparation}

Thirty-two extracted human third molars were selected for this study. The inclusion criteria were the absence of carious lesions, complete root formation and comparable coronal dimensions and anatomy. The teeth were stored in $0.1 \%$ thymol solution at $4{ }^{\circ} \mathrm{C}$ until the experiment onset. The preparation of teeth for this in vitro study followed the protocol described by Rocca et al. [32]. Standardised non-bevelled class II cavities (two surfaces OD or MO for teeth with no defect subsequent to extraction) were prepared in all teeth, with the proximal margin located $1.0 \mathrm{~mm}$ below the cementum-enamel junction (CEJ). Dimensions of the tapered preparations were $4.0 \mathrm{~mm}$ in width and $2.0 \mathrm{~mm}$ in depth at the bottom of the proximal box, and $5.0 \mathrm{~mm}$ in width and $3.0 \mathrm{~mm}$ in depth for the occlusal isthmus. All walls had about $10^{\circ}$ to $15^{\circ}$ of divergence. The 32 prepared teeth were randomly assigned to one of the four 


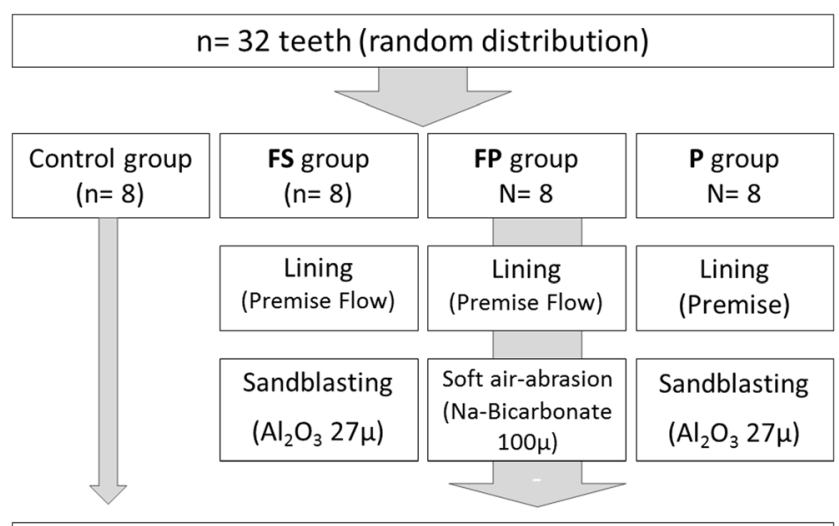

Restoration: Class II CEREC (IPS Empress CAD HT A2)

Adhesive cementation (Optibond FL \& Premise A2)

Pre-loading marginal adaptation evaluation (standard magnification 200x)

Mechanical loading: 1 million cycles, 100N @ 1.5Hz

Post loading marginal \& internal adaptation evaluation (standard magnification 200x)

Fig. 1 Flowchart describing the study experimental design and group distribution with selected procedures and products

groups (three experimental groups and one control group), according to the combination of restorative materials described in Table 1.

\section{Restorative procedures}

The sample preparation for receiving the $\mathrm{CAD} / \mathrm{CAM}$ restorations also followed the protocol described by Rocca et al. [32]. The cavities were treated with a three-step etch-and-rinse dentin bonding agent (Optibond FL, Kerr) before the application of a resinous base applied on all dentinal surfaces (about 1$\mathrm{mm}$ thickness) and extending over the gingival margin of the distal box, except in the control group, which had no base.
Two different lining materials were used for this purpose: a flowable nano-filled resin (Premise Flow A2, Kerr) in groups FS and FP or a nano-hybrid composite restorative resin (Premise A2, Kerr) in group P. After placement of the resinous bases, cervical margins were then relocated at the CEJ. The material characteristics and properties of the resinous bases are described in Tables 2 and 3.

\section{Design and manufacturing of CEREC CAD/CAM restorations}

All prepared teeth were powdered with titanium dioxide (Cerec Powder; Sirona, Bensheim, Germany), and optical impressions were taken with the Cerec 3D intraoral camera (Sirona). The inlays were fabricated using the Dental Database construction mode (software 3.10, Sirona) and were milled in leucite-reinforced glass-ceramic blocks (IPS Empress CAD HT, shade A2, Ivoclar Vivadent), with the Endo mode and the sprue located at the distal/mesial surface. The fit of the ceramic inlays into their respective cavities was controlled with low-viscosity polyvinylsiloxane (Fit Checker, GC, Tokyo, Japan) and under stereomicroscopy. The polishing of the ceramic inlays was performed with a diamond polishing system for ceramic restorations (OptraFine, Ivoclar-Vivadent, Schaan, Liechstentein) and flexible discs (Sof-Lex Pop-on XT, 3 M-ESPE, St. Paul, MN, USA).

\section{Adhesive cementation}

The CAD/CAM restorations were also cemented following the protocol described by Rocca et al. [32]. The internal surface of each ceramic restoration was etched for $60 \mathrm{~s}$ with $5 \%$ hydrofluoric acid gel (IPS Ceramic Etching Gel, Ivoclar Vivadent). After 60 -s rinsing and drying, a coupling silane (Monobond S, Ivoclar Vivadent) was applied and left undisturbed for $60 \mathrm{~s}$ followed by air-drying. A thin layer of bonding resin (Optibond FL, Kerr) was applied onto the inner surface of the restoration, and this bonding resin was left uncured and protected from light until cementation.

Composite lining layers in the cavities were submitted to different surface treatments: (a) sandblasting with $27 \mu \mathrm{m}$ aluminium oxide particles at 2-bar pressure (MicroEtcher ${ }^{\mathrm{TM}} \mathrm{CD}$,

Table 1 Restorative procedures under evaluation ( $n=8$ samples per group)

\begin{tabular}{llllll}
\hline Groups & Adhesive & Lining & Lining treatment & Restoration & Luting material \\
\hline CTR & OptiBond FL & None & None & IPS Empress CAD HT A2 & Premise A2 \\
FS & OptiBond FL & Premise Flow A2 & Sandblasting $\left(\mathrm{Al}_{2} \mathrm{O}_{3} 27 \mu\right)$ & IPS Empress CAD HT A2 & Premise A2 \\
FP & OptiBond FL & Premise Flow A2 & Soft air abrasion $(\mathrm{Na}$ Bi-carbonate $100 \mu)$ & IPS Empress CAD HT A2 & Premise A2 \\
$P$ & OptiBond FL & Premise A2 & Sandblasting $\left(\mathrm{Al}_{2} \mathrm{O}_{3} 27 \mu\right)$ & IPS Empress CAD HT A2 & Premise A2 \\
\hline
\end{tabular}


Table 2 List of products under investigation

\begin{tabular}{llll}
\hline Product & Product name (manufacturer) & Colour & Batch number \\
\hline $\begin{array}{l}\text { Conditioner } \\
\text { Dentin-bonding agent }\end{array}$ & Gel Etchant (Kerr) & - & 3133455 \\
& OptiBond FL ${ }^{\circledR}$ (Kerr) & - & Primer: 3139878 \\
Flowable resin & & & Adhesive:3139882 \\
Restorative resin & Premise $^{\circledR}$ Flow (Kerr) & A2 & 3044074 \\
Ceramic CAD/CAM Blocks & Premise $^{\circledR}$ (Kerr) & A2 & 3047603 \\
& IPS Empress CAD HT & A2 & M56172 \\
& Leucite-based glass ceramic & & \\
& blocks (Ivoclar Vivadent) & & \\
\end{tabular}

Danville Materials) (groups FS and P) or (b) soft air abrasion with $100 \mu \mathrm{m}$ sodium bicarbonate particles at 3-bar pressure (AirFlow Handy 2+, EMS, Nyon, Switzerland) (group FP). Enamel margins were acid-etched for $30 \mathrm{~s}$ with $37.5 \%$ phosphoric acid gel (Gel Etchant) prior to the application of one thin coat of adhesive resin (Optibond FL) which covered all surfaces of the preparation (composite and enamel) and left uncured. Specimens of the control group (CTR) were treated differently. The dentin surfaces of this group were refreshed by gentle work of a fine diamond bur under water cooling (Cerinlay No. 3025.018 FG), and the enamel was selectively etched for $30 \mathrm{~s}$ with $37.5 \%$ phosphoric acid gel (Gel Etchant) prior to a 15-s full cavity etching. The full adhesive system (Optibond FL Primer and Adhesive) was then applied, airthinned, and light-cured for $20 \mathrm{~s}$.

The restorations were cemented with Premise A2, using ultrasonic assistance (Cementation tip, EMS, Nyon, $\mathrm{CH}$ ). Each restoration surface was light-cured for $60 \mathrm{~s}$ under glycerine gel (Airblock), from occlusal, buccal and lingual directions to mimic clinical conditions (Bluephase, in mode High; Ivoclar Vivadent). The restorations were then finished and polished with a diamond polishing system for ceramic restorations (OptraFine) and flexible discs (Sof-Lex Pop-on XT) under continuous water cooling and descending roughness.

\section{Mechanical loading}

The stress test was carried out $24 \mathrm{~h}$ after cementation following a well-established protocol $[40,41]$. This fatigue test included simulation of pulpal pressure using $0.9 \%$ saline solution under a pressure of $14.1 \mathrm{~cm} \mathrm{H}_{2} \mathrm{O}$ during the loading phase [42] and 1,000,000 cycles with 100-N eccentric occlusal load at $1.5 \mathrm{-Hz}$ frequency, generated by electromagnets. Restored teeth were contacted by antagonist artificial cusps, made of stainless steel with a hardness similar to natural enamel (Vickers hardness: enamel $=320-325$; steel $=315$ ); the diameter of the cusps was $4 \mathrm{~mm}$. By having the specimen holder mounted on a hard rubber disc, a sliding movement of the tooth was produced between the first contact on an inclined plane and the central fossa. These conditions are taken to simulate about 4 years of clinical service $[40,43]$.

\section{Specimen evaluation}

\section{SEM evaluation of marginal and internal adaptation}

The SEM specimen evaluation was performed similarly to the study by Rocca et al. [32] before (pre-loading) and after completion of the loading phase (post-loading) on gold-sputtered

Table 3 Results for satisfactory marginal adaptation (mean percentages \pm standard deviation) with statistical analysis for the four groups (luting composite-tooth interface)

\begin{tabular}{|c|c|c|c|c|c|c|}
\hline \multirow[b]{2}{*}{ Groups } & \multicolumn{2}{|c|}{ Occlusal enamel } & \multicolumn{2}{|c|}{ Proximal enamel } & \multicolumn{2}{|c|}{ Cervical dentin } \\
\hline & Pre-load & Post-load & Pre-load & Post-load & Pre-load & Post-load \\
\hline CTR & $76( \pm 9)$ & $62( \pm 6)$ & $81( \pm 11)$ & $63( \pm 15)$ & $68( \pm 25)$ & $43( \pm 32)$ \\
\hline Diff. pre- and post-load (paired $t$ test) & \multicolumn{2}{|c|}{$14.531(p=0.0063) \mathrm{S} * *$} & \multicolumn{2}{|c|}{$17.696(p=0.0012) \mathrm{S}^{* *}$} & \multicolumn{2}{|c|}{$24.534(p=0.0041) \mathrm{S}^{* *}$} \\
\hline FS (Premise flow and sandblasting) & $82( \pm 7)$ & $71( \pm 9)$ & $83( \pm 14)$ & $58( \pm 20)$ & $84( \pm 15)$ & $66( \pm 21)$ \\
\hline Diff. pre- and post-load (paired $t$ test) & \multicolumn{2}{|c|}{$10.425(p=0.0169) \mathrm{S}^{*}$} & \multicolumn{2}{|c|}{$25.052(p=0.0026) \mathrm{S}^{* *}$} & \multicolumn{2}{|c|}{$18.760(p=0.0034) \mathrm{S}^{* *}$} \\
\hline FP (Premise flow and Prophy-jet) & $75( \pm 16)$ & $66( \pm 16)$ & $71( \pm 15)$ & $52( \pm 18)$ & $88( \pm 14)$ & $65( \pm 23)$ \\
\hline Diff. pre- and post-load (paired $t$ test) & \multicolumn{2}{|c|}{$9.578(p=0.0225) \mathrm{S}^{*}$} & \multicolumn{2}{|c|}{$19.769(p=0.0012) \mathrm{S}^{* *}$} & \multicolumn{2}{|c|}{$23.540(p=0.0026) \mathrm{S} * *$} \\
\hline P (Premise and sandblasting) & $87( \pm 9)$ & $72( \pm 8)$ & $75( \pm 9)$ & $52( \pm 12)$ & $83( \pm 25)$ & $54( \pm 27)$ \\
\hline Diff. pre- and post-load (paired $t$ test) & \multicolumn{2}{|c|}{$15.194(p=0.0009) \mathrm{S} * *$} & \multicolumn{2}{|c|}{$22.479(p=0.0002) \mathrm{S}^{* *}$} & \multicolumn{2}{|c|}{$28.315(p=0.0001) \mathrm{S}^{* *}$} \\
\hline ANOVA & NS & NS & NS & NS & NS & NS \\
\hline
\end{tabular}

${ }^{*} p<0.01 ; * * p<0.001$ 
epoxy resin replicas (Epofix; Struers, Rødrove, Denmark) of the restored teeth. The following segments were observed: enamel margins on the occlusal and proximal sides and cervical dentin margins on the proximal side, below the CEJ. The tooth-luting agent interface was analysed semi-quantitatively by scanning electron microscope (SEM) (Digital SEM XL20; Philips, Eindhoven, Netherlands) under $\times 200$ magnification, employing a recognised evaluation method $[44,45]$. The following morphological evaluation criteria were considered: continuous adaptation, overfilling, underfilling, marginal opening, marginal restoration or tooth fracture. Using proprietary software, the entire length of the restoration margins was examined, all sections and subsections of the margins identified, and then attributed an adaptation "grade" according to aforementioned parameters. The results for the restoration marginal adaptation, before and after loading phase, were then automatically calculated and represented as percentages of "satisfactory marginal adaptation" (no marginal opening, restoration or tooth fracture) for occlusal and proximal enamel margins, as well as cervical dentine.

At completion of the mechanical loading and after sample replication, the restored teeth were embedded in a slow selfcuring epoxy resin (Epofix, Struers, Rødrove, Denmark) and sectioned mesiodistally for internal adaptation evaluation, using a slow rotating saw (Isomet 11-1180; Buehlers, Lake Bluff, USA). The restoration internal adaptation was also assessed semi-quantitatively on gold-sputtered resin replicas under SEM at $\times 200$ magnification. The restoration internal adaptation was evaluated according to two criteria: perfect adaptation (continuity) and interfacial opening. Results were expressed as the percentage of satisfactory marginal adaptation (gap-free) for occlusal, axial and cervical dentin segments in relation to the entire length of the respective internal restoration interface examined. A single trained evaluator blindly performed all SEM observations.

\section{Statistical analysis}

No specific procedure was applied to control possible confounding factors, as plausibly limited only to tooth anatomy variations; teeth were then randomly assigned to either control or test groups. Results of the SEM analysis were submitted to a parametric statistical analysis, as suggested by normality tests. Comparison among groups for pre-load and post-load marginal adaptation and internal adaptation were then explored using an ANOVA test. Comparisons between pre-load and post-load marginal adaptation values for each group and restoration area were explored with a paired $t$ test. The confidence level was set to $95 \%(p<0.05)$. Normality tests and all other statistical calculations were performed with Instat 3.10 for Windows (Graphpad, San-Diego, CA, USA).

\section{Results}

The results of satisfactory marginal adaptation at the luting composite-tooth interface, before and after simulated occlusal loading, are presented in Table 3 and Figs. 2, 3 and 4. The results for internal adaptation following loading are presented in Table 4 and Figs. 5 and 6.

\section{Marginal adaptation}

There was no significant difference among groups in either pre- or post-loading condition for the three margin areas under evaluation. In both CTR (control) and P (Premise) groups, the standard deviation of cervical dentin values in the pre-load and particularly in the post-load condition, were markedly high, showing important variation in marginal adaptation quality. The differences in satisfactory adaptation between the pre- and the post-load conditions were significant for all groups in the three margin areas under evaluation.

\section{Internal adaptation}

There was no significant difference among groups for internal adaptation between composite and tooth or between composite and ceramic, along the three interface areas under evaluation.

\section{Discussion}

Phenomena such as leakage, pulpal complications and secondary caries induced by interface breakdown represent the major clinical failure patterns observed in all types of direct restorations [1,2]. This substantiates the relevance and need for marginal and internal adaptation testing, particularly if performed with a simulation of occlusal loading, pulpal pressure and moist environment $[12,13]$.

The pre-loading as well as post-loading marginal adaptation values of IPS Empress CAD inlays without or with different composite bases following various surface treatments did not reveal any significant difference among groups for the three areas under evaluation (occlusal enamel, proximal enamel and cervical dentin). Cervical dentin adaptation of restorations with flowable composite was however numerically superior to restorations without a liner (control group) or a Premise liner. However, the high standard deviations in the later two groups, both for pre- and post-loading conditions, explain the absence of a significant difference. Although such interpretation is not common, "abnormally" high standard deviations in fact suggest that related techniques are less reliable, leading in this case to less predictable marginal quality, despite comparable average adaptation. 
Fig. 2 Percentages of marginal adaptation for occlusal enamel margins expressed as percentage of "satisfactory marginal adaptation" before (pre) and after (post) loading

\section{Occlusal enamel}

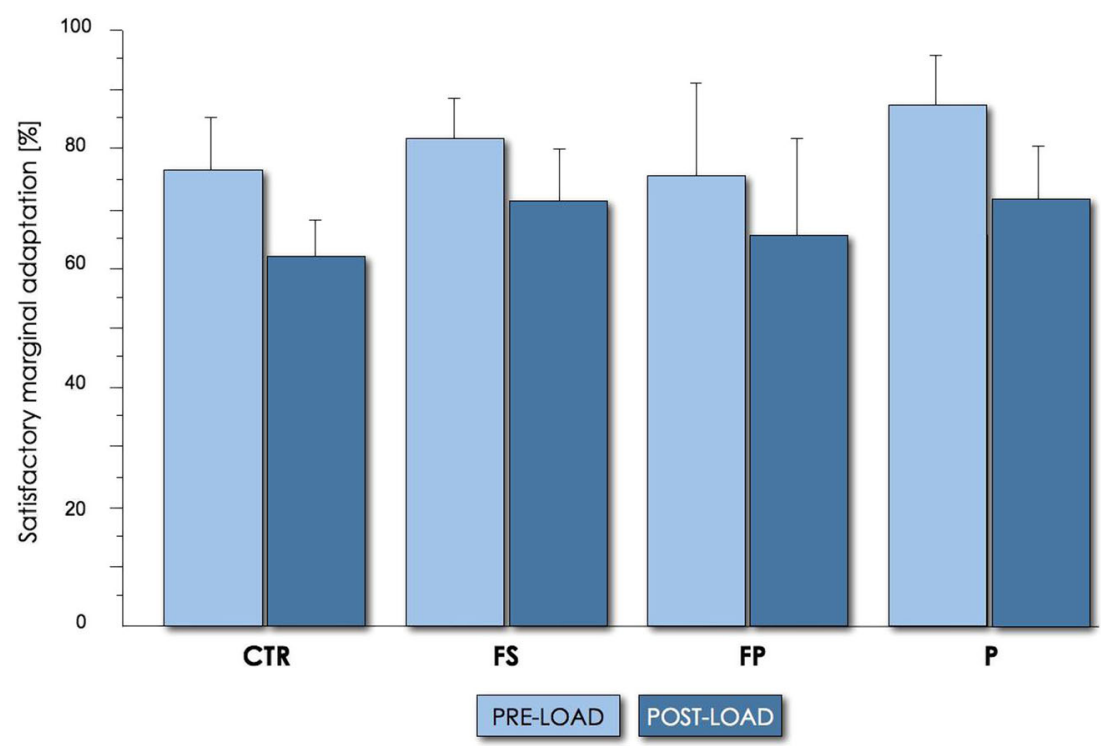

Loading significantly affected marginal restoration adaptation in all groups and all areas under evaluation, confirming the detrimental effect of simulated functional stresses. The magnitude of this reduction in satisfactory adaptation was higher in cervical dentin than in occlusal or proximal enamel, bringing the percentage of gap-free cervical margins quite low for the control and Premise groups (43.35 to $54.19 \%$ ), suggesting that defective restoration margin quality would occur over a medium period of function. This reduction in marginal adaptation of ceramic $\mathrm{CAD} / \mathrm{CAM}$ restorations appeared comparable to that observed in composite inlays, following an identical study protocol [32]. It also seemed comparable to the results of previous studies evaluating the fatigue behaviour of conventional fired porcelain or $\mathrm{CAD} / \mathrm{CAM}$ restorations [9-11, 46-50]. However, the interface between composite cement and tooth presented very consistent values of satisfactory internal adaptation between the control and experimental groups at the three interfaces under evaluation. The percentages of these groups were higher than those observed at the margins, suggesting a rather acceptable post-loading internal adaptation. For instance, the composite-tooth interface presented percentages of satisfactory adaptation in cervical dentin varying from $71.42 \%$ (CTR) to $84.28 \%$ (Premise flow with sandblasting), indicating that some marginal defects were likely superficial, with no such damaging effect on restoration quality, as previously interpreted. Here also, the variability
Fig. 3 Percentages of marginal adaptation for proximal enamel margins expressed as percentage of "satisfactory marginal adaptation" before (pre) and after (post) loading

\section{Proximal enamel}

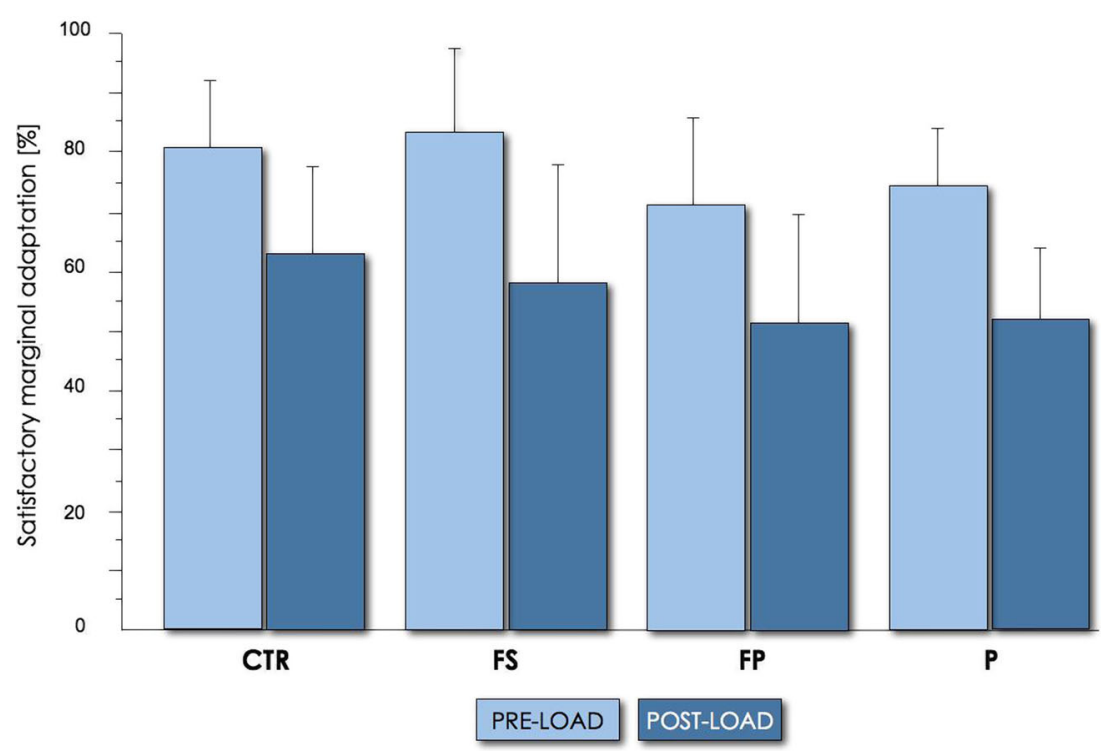


Fig. 4 Percentages of marginal adaptation for cervical dentin margins expressed as percentage of "satisfactory marginal adaptation" before (pre) and after (post) loading

\section{Cervical dentin}

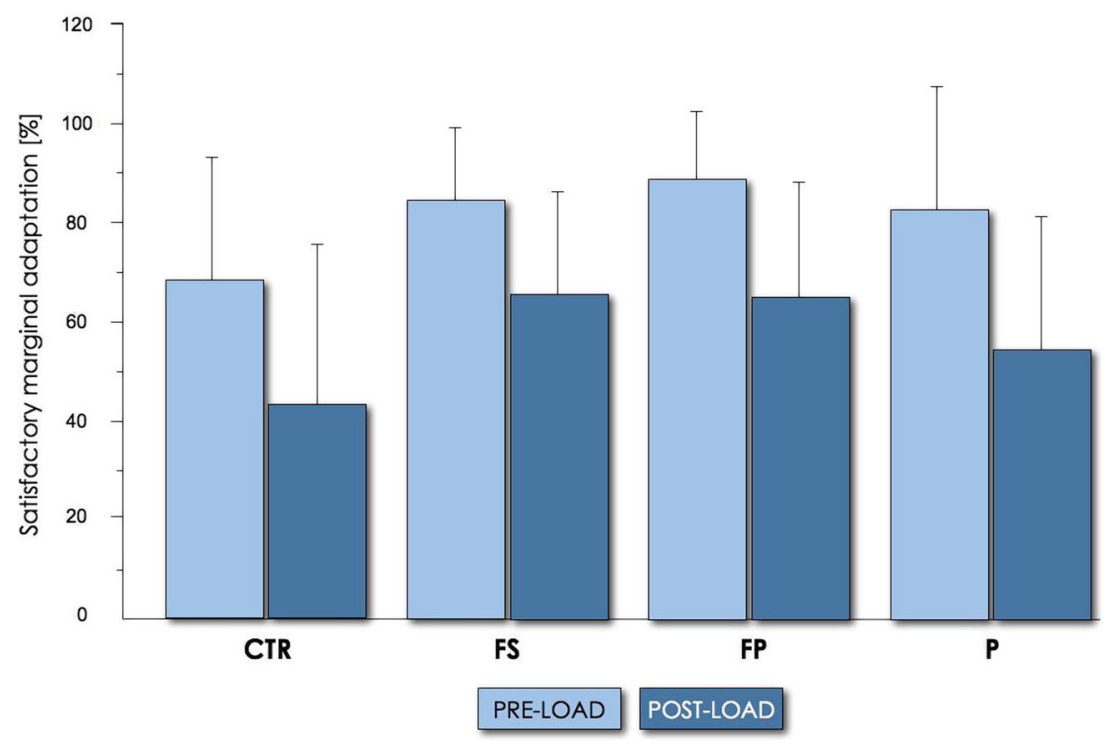

in internal adaptation results (as demonstrated by standard deviations) was quite high but with no specific trend among groups or areas. The interface between composite and etched ceramic proved totally satisfactory as demonstrated by percentages of continuous adaptation at $100 \%$ or at the lowest at $87.63 \%$ for the sandblasted flowable liner in cervical area. This demonstrated the reliability of bonding procedures to the IPS Empress CAD ceramic material and also confirms previous findings and the relatively high percentage of continuous ceramic-composite interface reported in similar fatigue studies $[10,47]$. These results are however in contrast with the findings of Bortolotto et al. [51], where CAD/CAM feldspathic porcelain inlays presented significantly lower percentages of continuous ceramic-composite interface in comparison with composite inlays.

The rationale for using a base or liner underneath large indirect class II restorations and, in particular, its use for cervical margin relocation (CMR) is multifactorial. Possible advantages include the facilitation of clinical procedures, a more conservative preparation, protection of the dentin during temporary phase and cementation $[21,52,53]$, and the bio- mechanical advantage, of a "stress breaking" layer concept [22]. The application of flexible liners and bases has been extensively described in the literature $[12,13,22,27$, 54-58], and it is considered that the presence of such a layer contributes to lower strains exerted on the adhesive interface by functional load. Excessive stresses can induce debonding, which in turn can trigger post-operative sensitivity (induced by hydrodynamic phenomena) [59] and may also reduce the restoration's tooth strengthening effect or allow fluid movements or bacterial penetration towards the pulp when the gap extends to the margin. Moreover, sealing the dentin and placing the liner following cavity preparation has been proven to increase bond strength and adhesive interface quality in full crown preparations, class II restorations and also veneers [60-64]. However, the thickness of the layer [57] as well as its material stiffness has shown various effects on restoration quality and adaptation. In a previous study, with a low E modulus liner, adaption of composite MOD inlays was found to be inferior to a restoration without a base, while an optimum "stress absorbing effect" was observed around 7-7.5 GPa [22]. In the same study, the restorative material presented

Table 4 Results for satisfactory internal adaptation (mean percentages \pm standard deviation) with statistical analysis for the four groups (luting composite-tooth interface and luting composite-ceramic interface)

\begin{tabular}{|c|c|c|c|c|c|c|}
\hline & Occlusal dentin & & Axial dentin & & Cervical dentin & \\
\hline Groups & Composite-tooth & Composite-ceramic & Composite-tooth & Composite-ceramic & Composite-tooth & Composite-ceramic \\
\hline CTR & $89( \pm 14)$ & $99( \pm 2)$ & $86( \pm 14)$ & $100( \pm 0)$ & $71( \pm 29)$ & $90( \pm 26)$ \\
\hline FS (Premise flow and sandblasting) & $98( \pm 2)$ & $100( \pm 0)$ & $90( \pm 17)$ & $100( \pm 0)$ & $84( \pm 27)$ & $88( \pm 23)$ \\
\hline FP (Premise flow and Prophy-jet) & $97( \pm 3.11)$ & $100( \pm 0)$ & $77( \pm 33.98)$ & $100( \pm 0)$ & $81( \pm 30.66)$ & $100( \pm 0)$ \\
\hline P (Premise and sandblasting) & $81( \pm 30)$ & $100( \pm 0)$ & $63( \pm 28)$ & $100( \pm 0)$ & $81( \pm 21)$ & $100( \pm 0)$ \\
\hline ANOVA & NS & NS & NS & - & NS & NS \\
\hline
\end{tabular}


Fig. 5 Percentages of internal adaptation for the compositeceramic interface expressed as percentage of "satisfactory marginal adaptation"
Interface composite-ceramic

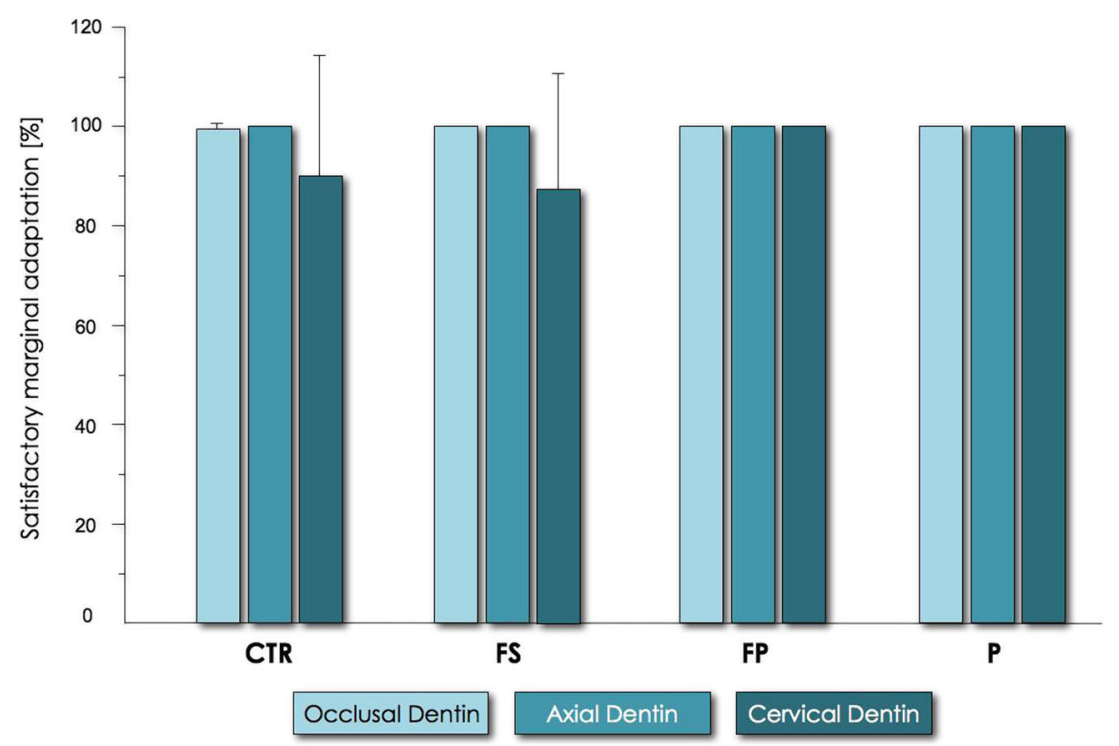

more interfacial defects immediately after placement, though this was attributed to a reduced wetting ability of the specific brand tested in that study.

In two recent studies, the cervical dentin adaptation of $\mathrm{CAD} / \mathrm{CAM}$ ceramic inlays placed over a liner made of restorative composite was either not significantly different from inlays placed directly on dentin [50], as observed following a similar number of loading cycles, or inferior to non-lined cavities following a reduced loading phase [65]. However, in the later study, different adhesives were used in the non-lined and lined cavities and this prevents the ability for proper comparison of both conditions. The use of self-adhesive composite cements as liners has led to inferior cervical dentin adaptation, and therefore, these products are not recommended for cervical margin relocation [65].

Among other parameters, a durable bond and cohesion between the restoration and the remaining tooth structure are mandatory for satisfactory long-term performance of indirect restorations. Mechanisms or procedures aimed at obtaining these goals are diverse. The polymerisation between the luting cement and the composite base (co-polymerisation) provides the strongest link but depends on the amount of residual free radicals which continue to decrease over time [66]. This progressive reduction takes place over 8 to 10 days, and the subsequent reduced potential for chemical bonding has no impact on a chair-side CAD/CAM approach because the restoration is
Fig. 6 Percentages of internal adaptation for the compositetooth interface expressed as percentage of "satisfactory marginal adaptation"

\section{Interface composite-tooth}

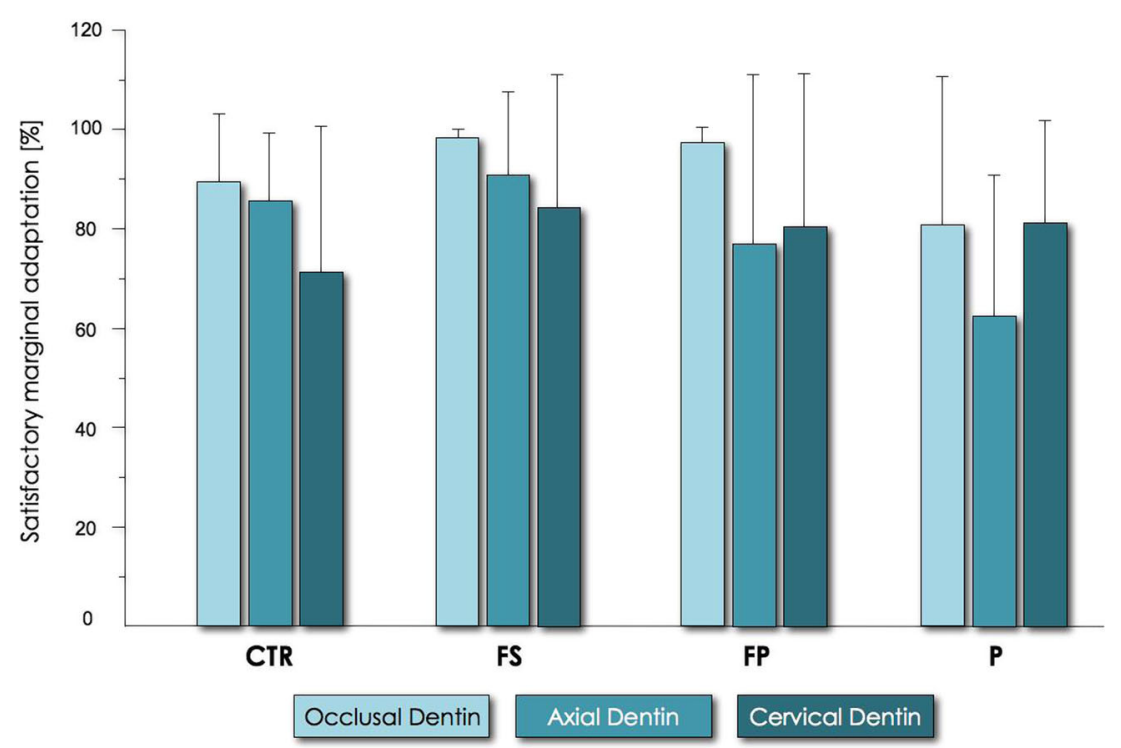


completed on the same day as the base is placed. In addition, many clinicians try to promote additional micro-mechanical retention through sandblasting or in general, any other roughening procedure (i.e. a diamond bur) before cementation [31, $67,68]$. In the present study, no or only small percentages of gaps were observed along the composite-ceramic interface suggesting that the combination of co-polymerisation and soft air abrasion or sandblasting was promoting a stable interface and that once again, the weakest interface of indirect adhesive restorations remains at the dentin level [22, 57, 58]. Sandblasting has however the potential to partially remove the adhesive layer and is therefore to be considered technically more sensitive [67]. Accordingly, soft air abrasion represents a feasible, gentler and reliable alternative for the cleaning and preparation of cavities before cementation.

Despite the absence of a significant difference in marginal or internal restoration adaptation, the present results suggest that placing a liner made of restorative or flowable composite, whatever the surface treatment applied is (soft air abrasion or sandblasting), leads to an adaptation similar to non-lined cavities with even more consistent margin quality, when applying a flowable liner. These observations fully support the use of CMR and composite liners underneath ceramic CAD/CAM inlays for deep proximal cavities, without any detrimental effect on restoration quality when compared to the classical treatment protocol and placement of the restoration directly in contact with dentin. Overall adaptation of large class II ceramic $\mathrm{CAD} / \mathrm{CAM}$ restorations to enamel (satisfactory adaptation varied from 52 to $63 \%$ post-load) or cervical dentin (satisfactory adaptation varied from 43 to $66 \%$ post-load) remains substantially unreliable and further material and clinical protocol improvements are needed to enhance restoration quality following functional loading.

\section{Conclusions}

Within the limitations of this in vitro experiment, the marginal adaptation of indirect class II inlays in occlusal and proximal enamel as well as cervical dentin areas have shown perfectible margin quality with a significant degradation following occlusal loading in all groups and segments under evaluation. Internal adaptation however presented higher proportions of satisfactory adaptation at the tooth-composite interface, demonstrating a rather good outcome of the technique. The composite-ceramic interface presented very few defects and can be considered of adequate quality. The null hypothesis was also confirmed, namely that the presence of a composite liner underneath ceramic $\mathrm{CAD} / \mathrm{CAM}$ restorations following different surface treatments did not affect restoration marginal or internal adaptation and appears therefore a suitable alternative to the conventional protocol for indirect class II inlays where the restoration is placed directly over dentin. The clinical relevance of this study is about using a composite base underneath indirect restorations to avoid additional preparation in the presence of undercuts and to relocate deep cervical margins to facilitate impression taking and control of cementation procedures.

Acknowledgments The authors acknowledge the support of manufacturers which graciously provided all the products tested in the present study.

Conflict of interest The authors of the manuscript certify that they have no proprietary, financial or any personal interest of any kind in any product or company that is mentioned in this article.

\section{References}

1. Hickel R, Manhart J (2001) Longevity of restorations in posterior teeth and reasons for failure. J Adhes Dent 3(1):45-64

2. Manhart J, Chen H, Hamm G, Hickel R (2004) Buonocore Memorial Lecture. Review of the clinical survival of direct and indirect restorations in posterior teeth of the permanent dentition. Oper Dent 29(5):481-508

3. Lu H, Stansbury JW, Dickens SH, Eichmiller FC, Bowman CN (2004) Probing the origins and control of shrinkage stress in dental resin-composites: I. Shrinkage stress characterization technique. J Mater Sci Mater Med 15(10):1097-1103

4. Peutzfeldt A, Asmussen E (2004) Determinants of in vitro gap formation of resin composites. J Dent 32(2):109-115

5. Stavridakis MM, Lutz F, Johnston WM, Krejci I (2003) Linear displacement and force induced by polymerization shrinkage of resin-based restorative materials. Am J Dent 16(6):431-438

6. Roulet JF, Salchow B, Wald M (1991) Margin analysis of posterior composites in vivo. Dent Mater 7(1):44-49

7. Davidson (1997) Factor influencing the quality of composite restorations; theory and practice. Bologna Int Symp 87-93

8. Dietschi D, Scampa U, Campanile G, Holz J (1995) Marginal adaptation and seal of direct and indirect Class II composite resin restorations: an in vitro evaluation. Quintessence Int 26(2):127-138

9. Mehl A, Kunzelmann KH, Folwaczny M, Hickel R (2004) Stabilization effects of $\mathrm{CAD} / \mathrm{CAM}$ ceramic restorations in extended MOD cavities. J Adhes Dent 6(3):239-245

10. Federlin M, Sipos C, Hiller KA, Thonemann B, Schmalz G (2005) Partial ceramic crowns. Influence of preparation design and luting material on margin integrity - a scanning electron microscopic study. Clin Oral Investig 9(1):8-17

11. Krifka S, Anthofer T, Fritzsch M, Hiller KA, Schmalz G, Federlin M (2009) Ceramic inlays and partial ceramic crowns: influence of remaining cusp wall thickness on the marginal integrity and enamel crack formation in vitro. Oper Dent 34(1):32-42

12. Dietschi D, Argente A, Krejci I (2013) Mandikos M In vitro performance of class I and II composite restorations: a literature review on nondestructive laboratory trials-part I. Oper Dent 38(5): E166-E181

13. Dietschi D, Argente A, Krejci I (2013) Mandikos M In vitro performanceof class I and II composite restorations: a literature review on nondestructive laboratory trials-part II. Oper Dent 38(5):E182-E200

14. Belli S, Inokoshi S, Ozer F, Pereira PN, Ogata M, Tagami J (2001) The effect of additional enamel etching and a flowable composite to the interfacial integrity of Class II adhesive composite restorations. Oper Dent 26(1):70-75 
15. Dietschi D, Bindi G, Krejci I, Davidson C (2002) Marginal and internal adaptation of stratified compomer-composite Class II restorations. Oper Dent 27(5):500-509

16. Peutzfeldt A, Asmussen E (2002) Composite restorations: influence of flowable and self-curing resin composite linings on microleakage in vitro. Oper Dent 27(6):569-575

17. Malmstrom HS, Schlueter M, Roach T, Moss ME (2002) Effect of thickness of flowable resins on marginal leakage in class II composite restorations. Oper Dent 27(4):373-380

18. Shortall AC, Baylis RL, Baylis MA, Grundy JR (1989) Marginal seal comparisons between resin-bonded Class II porcelain inlays, posterior composite restorations, and direct composite resin inlays. Int J Prosthodont 2(3):217-223

19. Dietschi D SR (1997) Adhesive metal free restorations: current concepts for the esthetic treatment of posterior teeth

20. Iida K, Inokoshi S, Kurosaki N (2003) Interfacial gaps following ceramic inlay cementation vs direct composites. Oper Dent 28(4): $445-452$

21. Dietschi D, Spreafico R (1998) Current clinical concepts for adhesive cementation of tooth-colored posterior restorations. Pract Periodontics Aesthet Dent 10(1):47-54, 22

22. Dietschi D, Olsburgh S, Krejci I, Davidson C (2003) In vitro evaluation of marginal and internal adaptation after occlusal stressing of indirect class II composite restorations with different resinous bases. Eur J Oral Sci 111(1):73-80

23. Inokoshi S, Shimada Y, Fujitani M, Otsuki M, Shono T, Onoe N, Morigami M, Takatsu T (1995) Monkey pulpal response to adhesively luted indirect resin composite inlays. Oper Dent 20(3):111-118

24. Inokoshi S, Fujitani M, Otsuki M, Sonoda H, Kitasako Y, Shimada Y, Tagami J (1998) Monkey pulpal responses to conventional and adhesive luting cements. Oper Dent 23(1):21-29

25. Lutz E, Krejci I, Oldenburg TR (1986) Elimination of polymerization stresses at the margins of posterior composite resin restorations: a new restorative technique. Quintessence Int 17(12):777-784

26. Friedl KH, Schmalz G, Hiller KA, Mortazavi F (1997) Marginal adaptation of composite restorations versus hybrid ionomer/ composite sandwich restorations. Oper Dent 22(1):21-29

27. Ausiello P, Rengo S, Davidson CL, Watts DC (2004) Stress distributions in adhesively cemented ceramic and resin-composite Class II inlay restorations: a 3D-FEA study. Dent Mater 20(9):862-872, 28

28. Magne P, Knezevic A (2009) Simulated fatigue resistance of composite resin versus porcelain $\mathrm{CAD} / \mathrm{CAM}$ overlay restorations on endodontically treated molars. Quintessence Int 40(2):125-133

29. Scott JA, Strang R, Saunders WP (1992) The plane of fracture and shear bond strength of three composite inlay systems. Dent Mater 8(3):208-210

30. Krejci I, Fullemann J, Lutz F (1994) Clinical and long-term scanning electron microscopic studies of composite inlays. Schweiz Monatsschr Zahnmed 104(11):1351-1356

31. Rodrigues SA Jr, Ferracane JL, Della Bona A (2009) Influence of surface treatments on the bond strength of repaired resin composite restorative materials. Dent Mater 25(4):442-451

32. Rocca GT, Gregor L, Sandoval MJ, Krejci I, Dietschi D (2012) In vitro evaluation of marginal and internal adaptation after occlusal stressing of indirect class II composite restorations with different resinous bases and interface treatments. "Post-fatigue adaptation of indirect composite restorations". Clin Oral Investig 16(5):1385-1393

33. Frankenberger R, Petschelt A, Kramer N (2000) Leucite-reinforced glass ceramic inlays and onlays after six years: clinical behavior. Oper Dent 25(6):459-465

34. Hayashi M, Wilson NH, Yeung CA, Worthington HV (2003) Systematic review of ceramic inlays. Clin Oral Investig 7(1):8-19
35. Molin MK, Karlsson SL (2000) A randomized 5-year clinical evaluation of 3 ceramic inlay systems. Int J Prosthodont 13(3):194-200

36. Thordrup M, Isidor F, Horsted-Bindslev P (2001) A 5-year clinical study of indirect and direct resin composite and ceramic inlays. Quintessence Int 32(3):199-205

37. Posselt A, Kerschbaum T (2003) Longevity of 2328 chairside Cerec inlays and onlays. Int J Comput Dent 6(3):231-248

38. Sjogren G, Molin M, van Dijken JW (2004) A 10-year prospective evaluation of $\mathrm{CAD} / \mathrm{CAM}$-manufactured (Cerec) ceramic inlays cemented with a chemically cured or dual-cured resin composite. Int J Prosthodont 17(2):241-246

39. Kramer N, Frankenberger R (2005) Clinical performance of bonded leucite-reinforced glass ceramic inlays and onlays after eight years. Dent Mater 21(3):262-271

40. Krejci I, Heinzmann JL, Lutz F (1990) The wear on enamel, amalgam and their enamel antagonists in a computer-controlled mastication simulator. Schweiz Monatsschr Zahnmed 100(11): $1285-1291$

41. Dietschi (2003) Evaluation of marginal and internal adaptation of adhesive class II restorations. Dissertation, ACTA University of Amsterdam

42. Ciucchi B, Bouillaguet S, Holz J, Pashley D (1995) Dentinal fluid dynamics in human teeth, in vivo. J Endod 21(4):191-194

43. Krejci I, Reich T, Lutz F, Albertoni M (1990) An in vitro test procedure for evaluating dental restoration systems. 1. A computer-controlled mastication simulator. Schweiz Monatsschr Zahnmed 100(8):953-960

44. Luescher B, Lutz F, Ochsenbein H, Muhlemann HR (1977) Microleakage and marginal adaptation in conventional and adhesive class II restoration. J Prosthet Dent 37(3):300-309

45. Roulet JF (1990) Degradation of dental polymers. 108-110

46. Dietschi D, Moor L (1999) Evaluation of the marginal and internal adaptation of different ceramic and composite inlay systems after an in vitro fatigue test. J Adhes Dent 1(1):41-56

47. Manhart J, Schmidt M, Chen HY, Kunzelmann KH, Hickel R (2001) Marginal quality of tooth-colored restorations in class II cavities after artificial aging. Oper Dent 26(4):357-366

48. Frankenberger R, Lohbauer U, Schaible RB, Nikolaenko SA, Naumann M (2008) Luting of ceramic inlays in vitro: marginal quality of self-etch and etch-and-rinse adhesives versus self-etch cements. Dent Mater 24(2):185-191

49. Frankenberger R, Kramer N, Appelt A, Lohbauer U, Naumann M, Roggendorf MJ (2011) Chairside vs. labside ceramic inlays: effect of temporary restoration and adhesive luting on enamel cracks and marginal integrity. Dent Mater 27(9):892-898

50. Zaruba M, Gohring TN, Wegehaupt FJ, Attin T (2012) Influence of a proximal margin elevation technique on marginal adaptation of ceramic inlays. Acta Odontol Scand

51. Bortolotto T, Onisor I, Krejci I (2007) Proximal direct composite restorations and chairside $\mathrm{CAD} / \mathrm{CAM}$ inlays: marginal adaptation of a two-step self-etch adhesive with and without selective enamel conditioning. Clin Oral Investig 11(1):35-43

52. Rocca GT, Krejci I (2007) Bonded indirect restorations for posterior teeth: from cavity preparation to provisionalization. Quintessence Int 38(5):371-379

53. Magne PaS R (2012) Deep margin elevation: a paradigm shift. Am J Esthet Dent 2:86-96

54. Kemp-Scholte CM, Davidson CL (1990) Marginal integrity related to bond strength and strain capacity of composite resin restorative systems. J Prosthet Dent 64(6):658-664

55. Kemp-Scholte CM, Davidson CL (1990) Complete marginal seal of Class V resin composite restorations effected by increased flexibility. J Dent Res 69(6):1240-1243

56. Ausiello P, Apicella A, Davidson CL (2002) Effect of adhesive layer properties on stress distribution in composite restorations - a 3D finite element analysis. Dent Mater 18(4):295-303 
57. Chuang SF, Jin YT, Liu JK, Chang CH, Shieh DB (2004) Influence of flowable composite lining thickness on Class II composite restorations. Oper Dent 29(3):301-308

58. Dewaele M, Asmussen E, Devaux J, Leloup G (2006) Class II restorations: influence of a liner with rubbery qualities on the occurrence and size of cervical gaps. Eur J Oral Sci 114(6):535-541

59. Brannstrom M (1966) The hydrodynamics of the dental tubule and pulp fluid: its significance in relation to dentinal sensitivity. Annu Meet Am Inst Oral Biol 23:219

60. Bertschinger C, Paul SJ, Luthy H, Scharer P (1996) Dual application of dentin bonding agents: effect on bond strength. Am J Dent 9(3):115-119

61. Paul SJ, Scharer P (1997) The dual bonding technique: a modified method to improve adhesive luting procedures. Int $\mathrm{J}$ Periodontics Restorative Dent 17(6):536-545

62. Dietschi D, Herzfeld D (1998) In vitro evaluation of marginal and internal adaptation of class II resin composite restorations after thermal and occlusal stressing. Eur J Oral Sci 106(6):1033-1042
63. Magne P, Douglas WH (1999) Porcelain veneers: dentin bonding optimization and biomimetic recovery of the crown. Int $\mathrm{J}$ Prosthodont 12(2):111-121

64. Magne P, So WS, Cascione D (2007) Immediate dentin sealing supports delayed restoration placement. J Prosthet Dent 98(3): 166-174

65. Frankenberger R, Hehn J, Hajto J, Kramer N, Naumann M, Koch A, Roggendorf MJ (2012) Effect of proximal box elevation with resin composite on marginal quality of ceramic inlays in vitro. Clin Oral Investig

66. Burtscher P (1993) Stability of radicals in cured composite materials. Dent Mater 9(4):218-221

67. Stavridakis MM, Krejci I, Magne P (2005) Immediate dentin sealing of onlay preparations: thickness of pre-cured Dentin Bonding Agent and effect of surface cleaning. Oper Dent 30(6): 747-757

68. Rocca GT, Krejci I (2007) Bonded indirect restorations for posterior teeth: the luting appointment. Quintessence Int 38(7):543-553 